\title{
El repertorio de poesía de tradición oral de Milagros Rego Carrasco y Dolores y Salud Oca Ramallo (Jerez de la Frontera, 1994)
}

\author{
The Orally Transmitted Poetry Repertoire \\ (Jerez de la Frontera, 1994) \\ Miguel Ángel PeÑA DíAZ \\ (Investigador independiente) \\ david-mario-cristina@hotmail.com \\ ORCID ID: 0000-0002-3943-6034
} by Milagros Rego Carrasco and Dolores and Salud Oca Ramallo

\begin{abstract}
This article presents the repertoire, by Milagros Rego Carrasco and Dolores and Salud Oca Ramallo, of orally transmitted poetry, collected during 1994 in Jerez de la Frontera, Cádiz.
\end{abstract}

KEYWORDS: Orally transmitted poetry, Jerez de la Frontera, 1994
RESUMEN: Este artículo ofrece el repertorio de poesía de tradición oral de Milagros Rego Carrasco y Dolores y Salud Oca Ramallo recogido en 1994 en Jerez de la Frontera (Cádiz).

PALABRAS-CLAVE: poesía de tradición oral, Jerez de la Frontera, 1994

«Mira por dónde, estoy leyendo lo que aprendí cuando era una niña». Estas fueron las palabras que Milagros Rego Carrasco emitió el día que les di a leer a mis alumnas, en el Centro Cívico Primero de Mayo de Jerez de la Frontera, el romance de Blancaflor y Filomena, romance que ella misma me había cantado unos días antes. Esta excepcional transmisora de la poesía de tradición oral experimentó una gran satisfacción cuando vio que el tesoro que portaba su memoria desde su niñez, y que nunca había visto en letra impresa, era el recurso que utilizaba su maestro para la enseñanza de la lecto-escritura. Esto sucedió porque traté de hacer uso del método global para la enseñanza de la lectura y escritura, del brasileño Paulo Freire, y para ello no partí de una sola palabra o frase generadora para llegar a sus sílabas, letras y sonidos, sino de un texto completo. En este caso consideré que, tomar textos extraídos de las memorias de las alfabetizandas sería una ventaja para llevar a cabo el proceso de enseñanza-aprendizaje de la lectura y la escritura con el método global, de ahí que optara por el uso de versiones de textos pertenecientes a la literatura de tradición oral.

Llamamos en Jerez zambomba, además de al instrumento, a la fiesta para celebrar la llegada de la Navidad. Eran fiestas celebradas antaño en los patios de las casas de vecinos o en la intimidad de las familias, en las que se reunían las gentes formando corros para cantar un repertorio de canciones tradicionales marcado por el son de la zambomba, panderetas, almireces, botellas de anís frotadas con alguna cuchara, palmas y poco más. 
Se bebía aguardiente o algún vino de la tierra, y se comía productos como pestiños y buñuelos, todo ello compartido por los participantes.

Fueron dos zambombas celebradas en diciembre de 1993 — una en la asociación de vecinos del barrio de Santiago, «La muralla», y la otra en la asociación de alfabetización «Zona Oeste», en el centro cívico Primero de Mayo, ambas asociaciones ubicadas en Jerez de la Frontera - las que me impulsaron a seguir recolectando romances y canciones tradicionales. En aquellas dos zambombas, entre aquellas señoras alumnas nuestras que acudían al centro cívico Primero de Mayo para aprender a leer y escribir, pude comprobar que algunas destacaban como excelentes transmisoras de esta parcela de la literatura de tradición oral. Entre panderetas, risas, aguardiente, bailes, pestiños, etc., los romances y las canciones tradicionales brotaban de forma espontánea en la fiesta.

Pasados algunos días de la celebración de estas zambombas, cogí la grabadora y pedí a Milagros Rego Carrasco, de 63 años por aquellas fechas, que me cantara algunas de estas «coplas antiguas». Ya en su casa, la informante no solo me cantó el frondoso repertorio de poesía tradicional que por aquel entonces recordaba y que aquí transcribimos, sino que me facilitó una nueva encuesta en la que cantó con sus cuñadas Dolores y Salud Oca Ramallo, también excepcionales trasmisoras del género. Tras varias encuestas realizadas durante los meses enero, febrero y marzo de 1994, pude reunir el repertorio de textos de tradición oral que a continuación presentamos.

En lo concerniente a los títulos de los textos de este repertorio, en general son aleatorios, aunque algunos otros son aquellos con los que se les conocen en el mundo académico. Podrían también no haber llevado títulos, pero he preferido asignarles uno al gusto del recopilador, los cuales no son en absoluto fijos. En algunos casos simplemente he utilizado el primer verso del texto como título.

Con respecto a las transcripciones de los textos, he intentado siempre conseguir que las mismas reproduzcan fielmente los textos que las informantes actualizaron en el acto en los que fueron cantados. A veces les fue imposible recordar algunos versos de los textos y las transcripciones recogen estas lagunas de sus memorias con puntos suspensivos. En los casos en los que lo olvidado ha sido un fragmento mayor de texto y las informantes los han narrado en prosa, el contenido de lo olvidado lo hemos transcrito entre corchetes.

Relacionado también con las transcripciones, he de dejar constancia de la dificultad que supone puntuar un poema de tradición oral. Unas veces la persona que, cantando, transmite estos textos hace pausas métricas o impuestas por las músicas que soportan estos textos; otras, el lenguaje poético tradicional se rige por criterios expresivos que no casan con la lengua escrita. De ahí que la puntuación de los textos transcritos aquí sea la interpretación que hago, según mi lectura, — evidentemente no la única- para hacérselos comprensibles al lector.

Por último, en cuanto a la ortografía, se ha respetado las variantes del andaluz. Esto no quiere decir que los textos hayan sido transcritos fonéticamente. Por ejemplo, las consonantes finales de palabras $n, l, s, d, z, r$, que apenas se aprecian en la oralidad de las transmisoras, sí aparecen en las transcripciones, a no ser que impidan sinalefas, en cuyo caso están entre paréntesis. Asimismo los vocablos que están generalizados en todos los niveles del habla andaluza (como por ejemplo pa por para, na por nada, to por todo) o la pérdida de la $d$ intervocálica (como en soldao por soldado, toa por toda, quería por querida) se transcriben tal cual los pronuncian. 
A continuación, y agradeciendo enormemente a las verdaderas protagonistas de este artículo su generosidad por el regalo que nos hicieron en los momentos en que nos cantaron estos poemas tradicionales, damos paso a ellos.

\section{Los quintos}

Versión de Jerez de la Frontera. Cantada por Milagros Rego Carrasco, 63 años. Recogida en enero 1994 por Miguel Ángel Peña Díaz.

Ya se van los quintos, mare, ya se llevan a mi Pepe, ya no tengo quien me lleve horquillas para el roete.

$5 \quad$ Y a los soldaditos

se los llevan ya al campo del moro para pelear.

Ya se van los quintos, mare,

10 yo no me quisiera ir porque dejo en esta calle un pimpollo y otro a medio abrir.

Y a los soldaditos se los llevan ya

15 al campo del moro para pelear.

\section{Qué bonito está un soldao}

Versión de Jerez de la Frontera. Cantada por Milagros Rego Carrasco, 63 años. Recogida en enero 1994 por Miguel Ángel Peña Díaz.

Qué bonito está un soldao en la puerta de un cuartel con la gorrita en la mano saludando al coronel.

5 A la guerra, soldados valientes, a la guerra con gran devoción, a la guerra se van los valientes de toa la nación.

¡Ay, con sal, sin sal te quiero! 
10 Qué bonito está un soldao cuando está haciendo la cama, tira la mantita y dice:

«iQuién se volviera una dama!»

A la guerra, soldados valientes,

15 a la guerra con gran devoción, a la guerra se van los valientes de toa la nación.

Qué bonito está un soldao cuando está comiendo rancho,

20 tira la cuchara y dice:

«iQué duros están los garbanzos!»

\section{En esta calle a lo largo}

Versión de Jerez de la Frontera. Cantada por Milagros Rego Carrasco, 63 años. Recogida en enero 1994 por Miguel Ángel Peña Díaz.

En esta calle a lo largo hay un gavilán tendido que dice que va a sacar la paloma de su nido.

$5 \quad$ Eso será si no hubiera mocito en esta ciudad que saliera a la defensa y matara al gavilán.

En esta calle hay un niño

10 que se la da de valiente, con una espada de caña viene asustando a la gente. Saca la espada, cobarde, arrástrala por los suelos

15 y si no mate que espante la gente que está muriendo.

En esta calle hay una niña que se la da de que vale, si tos fueran de mi gusto, 20 no la camelaba nadie.

Vengo de subir, subir, al puerto de Guadarrama para recoger la sal que mi moreno derrama. 
25 Y después de haber subido y de haber pisao la nieve, ya no me quieres, chiquillo, chiquillo, ya no me quieres.

\section{Entré en un jardín de Venus}

Versión de Jerez de la Frontera. Cantada por Milagros Rego Carrasco, 63 años. Recogida en enero 1994 por Miguel Ángel Peña Díaz.

Entré en un jardín de Venus

cinco capullos corté,

fueron los cinco sentidos

que yo puse en tu querer.

5 Ábreme la puerta, ciérrame el postigo, échame el pañuelo, que yo vengo herido. $\mathrm{Po}^{1}$ si viene herido,

10 vete al hospital que allí están las monjas de la caridad, que curan de balde y no llevan na.

15 De los cinco, te doy uno y yo me quedo con cuatro por haberte conocido $\mathrm{y}$ haberte querido tanto.

Ábreme la puerta,

20 ciérrame el postigo, échame el pañuelo, que yo vengo herido. Po si viene herido, vete al hospital

25 que allí están las monjas de la caridad, que curan de balde y no llevan na.

De los cuatro, te doy uno

30 y yo me quedo con tres por haberte conocido

\footnotetext{
${ }^{1}$ Po por «pues».
} 
y haberte querido bien.

Ábreme la puerta, ciérrame el postigo,

35 échame el pañuelo, que yo vengo herido. Po si viene herido, vete al hospital que allí están las monjas

40 de la caridad, que curan de balde y no llevan na.

De los tres, te doy uno y yo me quedo con dos

45 por haberte conocido y haberte querido yo.

Ábreme la puerta, ciérrame el postigo, échame el pañuelo,

50 que yo vengo herido. Po si viene herido, vete al hospital que allí están las monjas de la caridad,

55 que curan de balde y no llevan na.

De los dos, te doy uno y yo me quedo con otro por haberte conocido

60 y haberte ido con otro.

Ábreme la puerta, ciérrame el postigo, échame el pañuelo, que yo vengo herido.

65 Po si viene herido, vete al hospital que allí están las monjas de la caridad, que curan de balde

70 y no llevan na.

El último que me queda te lo doy de malas ganas por haberte conocido 
sentrañitas $^{2}$ de mi alma.

75 Ábreme la puerta, ciérrame el postigo, échame el pañuelo, que yo vengo herido. Po si viene herido,

80 vete al hospital que allí están las monjas de la caridad, que curan de balde y no llevan na.

\section{Calle de San Francisco}

Versión de Jerez de la Frontera. Cantada por Milagros Rego Carrasco, 63 años. Recogida en enero 1994 por Miguel Ángel Peña Díaz.

Calle de San Francisco, ¡qué larga y serena! Tiene cuatro faroles sin merecerlas

5 y bien merecía. Los cañones, los cañones de la artillería en medio un castillo, donde hombres,

10 donde hombres, mujeres y niños debían de estar. Calla, lengua, calla, lengua, y no hables más.

Muchas con el achaque

15 de tomar el fresco, se asoman a la ventana y con gran contento sus madres las llaman: -Mariquilla,

20 Mariquilla, cierra la ventana.

- Ya voy, mamá, que estoy viendo a la gente pasar-. Y era porque estaba con el novio pelando la pava.

25 Estando yo en mi puerta

\footnotetext{
${ }^{2}$ Diminutivo de entrañas. La $s$ inicial es una prótesis.
} 
y con otras dos, pasó un marinerito y me preguntó:

— ¿Dónde está la plaza?

30 Yo le dije,

yo le dije:

-Vuelva usted la esquina,

calle de Medina,

calle Doña Blanca;

35 derechito,

derechito salga uste(d) a la plaza

donde venden pan

y también molletes;

cuidadito,

40 cuidadito con aquellas gentes

que roban pañuelos

y la bolsa,

y la bolsa que lleva el dinero-.

Allá arriba, arribita

45 la luz de la perla

donde se ven bajar

los novios y las novias

de pelar la pava.

¡Ay, la luz,

$50 \quad$ la luz de la perla!

\section{Trescientos cincuenta escalones}

Versión de Jerez de la Frontera. Cantada por Milagros Rego Carrasco, 63 años. Recogida en enero 1994 por Miguel Ángel Peña Díaz.

Trescientos cincuenta escalones

tiene la escalera

que vamo(s) a subir.

En el centro tiene cinco rosas.

$5 \quad$ iQué hora más hermosa

de mayo y abril,

de mayo y abril!

Que trescientos cincuenta escalones

tiene la escalera

10 que vamo(s) a subir.

Alegría que ya viene el día

$\mathrm{y}$ viene alumbrando

los rayos del sol.

A los titirimundo piloto 
15 pasa su(s) estaciones nuestra embarcación. ¿Qué linda ocasión, qué linda ocasión!

Que la hostia por chica que sea

20 lleva cuerpo y sangre

de nuestro Señor.

María, barca de plata, San José, los remos, y el Niño, el timón,

25 el Espíritu Santo, el piloto, pasa su(s) estaciones nuestra embarcación. ¿Qué linda ocasión, qué linda ocasión!

30 Que la hostia por chica que sea lleva cuerpo y sangre de nuestro Señor.

Allá arriba en el monte Calvario

35 la rueda de un coche a un niño cogió, y su madre, triste y afligida, los escapularios

40 del Carmen le echó. ¡Mira qué dolor!

Allá arriba en el monte Calvario la rueda de un coche

45 a un niño cogió.

\section{Benito}

Versión de Jerez de la Frontera. Cantada por Milagros Rego Carrasco, 63 años. Recogida en enero 1994 por Miguel Ángel Peña Díaz.

Debajo (d)el barranco

vive Benito.

Tiene puesta una tienda porque está rico

5 y vende peinetas, peinecillos, también pañoletas y otras cosas más, que los mozos no pueden comprar, 
y otras cosas menos,

10 que los mozos no tienen dinero.

Y yo le dije: «Benito,

saca un pañuelo

con las listas azules

que es pa un recuerdo,

15 que es pa una novia

que la tengo siempre en la memoria».

Y al punto sacó

un pañuelo que por él pidió

cincuenta reales.

20 ¡Ay, rumbales,

qué caro y qué vale!

Se dicen las mocitas

una a la otra

y a la misa del gallo

25 vamos nosotras.

Se van paseando

las esquinas las van registrando

y el novio la mira

tan hermosa, qué quié ${ }^{3}$ que te diga.

30 Niña, dame los peines

y agua colonia

para peinarme el pelo

que voy de novia.

Que voy de novia, niña,

35 que voy de novia,

niña, dame los peines

y agua colonia.

Que vivan las sevillanas, que viva la Macarena,

40 que mueran las gentes chulas,

que viva la Nochebuena.

\section{Pa qué me das el pañuelo}

Versión de Jerez de la Frontera. Cantada por Milagros Rego Carrasco, 63 años. Recogida en enero 1994 por Miguel Ángel Peña Díaz.

¿Pa qué me das el pañuelo

con puntas, para llorar,

si sabes que soy soldado

\footnotetext{
3 quié por «quiere». Síncopa de la consonante $r$ por necesidades métricas.
} 
$5 \quad$ Y anda y no te cases,

que a la orilla del mar he venido

tan solo por verte,

que me han dicho que estás a la muerte.

Jesús, qué mentira,

10 los amores me traen arrendida ${ }^{4}$

por un ganadero.

Mira, niña, que soy artillero

de Puerto Real

y a la niña la van a embarcar

15 en un mercantil.

Mira, niña, que vas a morir.

Déjalo que muera,

que muriendo se acaba la guerra,

que ya y ya ya,

20

que ya y ya ya.

\section{Don Bueso}

Versión de Jerez de la Frontera. Cantada por Milagros Rego Carrasco, 63 años. Recogida en enero 1994 por Miguel Ángel Peña Díaz.

Al pasar por Casablanca pasé por la morería, yo vi una mora lavando, lavando en la fuente fría.

Yo le dije: -Mora bella, yo le dije: -Mora linda, deja beber mi caballo de este agua cristalina.

5 - No soy mora, caballero, que soy cristiana cautiva, me cautivaron los moros día de Pascua Florida.

- Si quieres venir a España, aquí en mi caballería.

- ¿Y los pañuelos que lavo, dónde yo los dejaría?

- Los finos, finos de Holanda, aquí en mi caballería,

10 y los que no valgan nada por el río abajo irían.

- ¿Y mi honra, caballero, dónde yo la dejaría?

- Yo juro de no tocarte hasta los montes de oliva-.

Al llegar a aquellos montes la mora se echó a llorar.

_ ¿Por qué lloras, mora bella?, ¿por qué lloras, mora linda?

15 - Lloro porque en estos montes mi padre a cazar venía

con mi hermano Moralejo y toda su compañía.

Mi padre se llama Juan, mi madre, Doña María, y mi hermano que yo tengo se llama José María.

- ¡Ay, Dios mío, lo que oigo, Virgen Sagrada María!

20 Pensé de traer mujer y traigo una hermana mía-.

- ¿Cuánto daría usted, madre, por ver a su hija querida?

- Le daría toda mi riqueza y también la vida mía.

\footnotetext{
${ }^{4}$ La vocal $a$ inicial es una prótesis.
} 
-Abre puertas y balcones, ventanas y celosías que ya apareció la dama que llora de noche y día.

\section{Las tres cautivas}

Versión de Jerez de la Frontera. Cantada por Milagros Rego Carrasco, 63 años. Recogida en enero 1994 por Miguel Ángel Peña Díaz.

A la verde, verde, y a la verde oliva donde cautivaron a esas tres cautivas. El maldito moro que las se robó ${ }^{5}$ a la reina mora fue y se la entregó.

5 -Toma, reina mora, estas tres cautivas, toma, reina mora, para que te sirvan.

- ¿Y qué oficio tienen esas tres cautivas?

- La mayor lavaba, la menor cosía, y la más pequeña por agua le iba.

$10-i$ Y cómo se llaman esas tres cautivas?

- La mayor Rosaura, la menor Lucía, y la más pequeña se llama María-. $\mathrm{Y}$ a los tres viajes que a la fuente iba se ha encontrao a un hombre que en ella venía,

15 poderoso padre de las tres cautivas.

- ¿Qué hace usted, buen hombre, y en la fuente fría?

-Guardando que lleguen esas tres cautivas.

- ¿Y cómo se llaman esas tres cautivas?

- La mayor Rosaura, la menor Lucía,

20 y la más pequeña se llama María.

- Pos $^{6}$ usted mi padre, yo seré su hija.

Espera usted, padre, que vaya y lo diga-

- ¿No sabes, Rosaura, y hermana Lucía

que padre no(s) espera en la fuente fría?-

25 La mayor lloraba, la menor reía

y la más pequeña las consolaría.

-No llores, Rosaura, ni hermana Lucía, como el moro se entere nos castigaríaY el maldito moro que las escuchó

30 en una mazmorra allí las metió.

\section{La bastarda y el segador}

Versión de Jerez de la Frontera. Cantada por Milagros Rego Carrasco, 63 años. Recogida en enero 1994 por Miguel Ángel Peña Díaz.

\footnotetext{
${ }^{5}$ El orden natural sería que se las robó.

${ }^{6}$ Pos por «pues».
} 
Salieron tres segadores a segar fuera de casa y uno de los segadores lleva ropita de Holanda. Llegaron a cierto pueblo, se pasean por la plaza, y una dama en un balcón del segado(r) está prendada

5 y lo ha mandado a llamar con una de sus criadas.

— ¿Qué me quiere usted, señora, qué me quiere, qué me manda?

- Quiero que me siegue usted un poco de cebada.

—Dime usted dónde la tiene, dónde la tiene sembrada.

-No está en alto, ni está en bajo, ni está en cerro, ni en cañada,

10 que está en medio dos columnas que las dos tiene mi alma.

-Esa cebada, señora, no son para yo segarla, que son pa duque marqueses o par $^{7}$ dueño de la casa.

- No se vaya, segador, que para usted están sembrada-.

Ha segado siete gavillas y a las doce se alevanta ${ }^{8}$.

15 - No se vaya, segador, que le voy a dar las pagas-.

Le ha dado dos mil doblones en un pañuelo de Holanda que el pañuelo vale más que las pagas que le daba.

$Y$ al otro día siguiente las campanas redoblaban.

— ¿Quién se ha muerto, quién se ha muerto? -El segador que segaba.

20 - No se ha muerto, no se ha muerto, que lo ha matado una dama-.

El dinero pa' $1^{9}$ entierro y el pañuelo pa la cara.

Aquí se acabó la historia del segador y la dama.

\section{Santa Isabel}

Versión de Jerez de la Frontera. Cantada por Milagros Rego Carrasco, 63 años. Recogida en enero 1994 por Miguel Ángel Peña Díaz.

-Mi prima, Santa Isabel, está solita en su parto.

Si quisiera(s), esposo mío, yo le acompañara un rato-.

Y San José dice, con mucha alegría,

en su dulce nombre que vaya María.

5 La Virgen va caminando por los montes Daguilea ${ }^{10}$.

Santa Isabel la recibe en sus brazos presenciada

y San Juan Bautista, que en su vientre estaba,

se hincó de rodillas y a Dios le adoraba.

La gente de la ciudad con tal salían a verla

10 con una voz que decía: - Ahí viene la Virgen María.

Jesús, ¡qué contento!, Jesús, ¡qué alegría!,

que ya viene ahí la Virgen María-

San José como sabía que aquella noche llegaba,

\footnotetext{
${ }^{7}$ par por «para».

${ }^{8}$ La vocal $a$ inicial es una prótesis.

${ }^{9}$ pa'l es la contracción de la preposición «para» y el artículo «el».

${ }^{10}$ Daguilea es la contracción de la preposición «de» y el sustantivo «Galilea».
} 
antes de las oraciones la cena le preparaba.

15 -Jesús, iqué contento!, Jesús, iqué alegría!, que ya viene ahí mi esposa María-.

- Siéntate, esposa del alma, siéntate, lucero mío,

siéntate y te contaré lo que sin tu presencia yo tenía.

$\mathrm{Al}$ verme tan solo de ti me acordaba

20 y en mi soledad de pena lloraba.

Siéntate, esposa del alma. ¿Cómo siguen tus parientes?

- Todos buenos y a Dios gracias, todos contentos y alegres.

Juan se llama el niño de mi prima hermana,

como es tan chiquito lo quiere y lo ama.

\section{La Samaritana}

Versión de Jerez de la Frontera. Cantada por Milagros Rego Carrasco, 63 años. Recogida en enero 1994 por Miguel Ángel Peña Díaz.

Un día que el Redentor Santa María caminaba fatigada de calor por descansar se sentaba junto al pozo de Japón.

5

A lo lejos vio venir la misma que lo guardaba con el cántaro en la mano y era la Samaritana.

- Samaritana, te ruego, si el cántaro tiene agua, por tu marido en compaña.

- Señor, no tengo marido- dice la Samaritana.

- Siete maridos tuviste y ya ninguno te ama-

10 Al punto, la pecadora le volvió al mundo la espalda y así la volvamos todos, como la Samaritana.

\section{Mal casada}

Versión de Jerez de la Frontera. Cantada por Milagros Rego Carrasco, 63 años. Recogida en enero 1994 por Miguel Ángel Peña Díaz.

Mi madre me casó chiquita y bonita, ya ya ya, ${ }^{11}$

con un buen muchacho que yo no lo quería.

La noche de novios entraba y salía

por la puerta falsa de la sacristía.

5 Yo lo vi entrar an ${ }^{12}$ casa la quería.

Yo lo escuché que decía:

«A ti te daré sayas y mantillas

y a mi mujer, palo y mala vida».

Yo lo vi venir de casa la quería.

11 Tras cada segundo hemistiquio se dice «ya ya ya» y se repite dicho hemistiquio.

12 an por «en» 
10

—Ábreme la puerta

que vengo cansado de buscar la vida.

-Tú vienes cansado de casa la quería-

Él me tiró un zapato, yo le tiré la silla.

Él fue al hospital, yo fui a la casilla.

15 Él estuvo tres meses, yo estuve dos días.

\section{Alba Niña}

Versión de Jerez de la Frontera. Cantada por Milagros Rego Carrasco, 63 años. Recogida en enero 1994 por Miguel Ángel Peña Díaz.

Mañanita, mañanita, mañanita Santipón, yo vi a una señorita sentadita en su balcón, muy peinada y muy lavada y en la cabeza una flor.

Ha pasado un caballero y de ella se enamoró.

5 - iQuién durmiera contigo, luna! ¡Quién durmiera contigo, sol!

- Mi marido no está en casa, que está en los montes León!-

Ha llegado el caballero y con ella se acostó.

Estando en estas razones, y a la puerta llegó.

- ¿De quién será aquel caballo que en mi cuadra veo yo?

10 - Tuyo, tuyo, maridito, que mi padre te lo dio, para que fuera(s) a los montes, a los montes de León.

- iViva tu padre cien años que caballo tengo yo!-

Estando en estas razones, para la percha miró.

- ¿De quién será esa camisa que en mi percha veo yo?

15 - Tuya, tuya, maridito, que mi padre te la dio, para que fuera(s) a los montes, a los montes de León.

- iViva tu padre cien años que camisa tengo yo! -

Estando en estas razones, para la percha miró.

- ¿De quién es esa chaqueta que en mi percha veo yo?

20 - Tuya, tuya, maridito, que mi padre te la dio, para que fuera(s) a la boda de mi hermana la mayor.

- iViva tu padre cien años que chaqueta tengo yo!

— ¿De quién son esos zapatos que en mi suelo veo yo?

- Tuyos, tuyos, maridito, que mi padre te los dio

25 para que fueras a los montes de León.

- iViva tu padre cien años que zapatos tengo yo.

- ¿Quién es ese caballero que en mi cama veo yo?

-Es un primo mío que vino de Nueva York-.

La ha cogío por los pelos y al padre se la llevó.

30 - Tome usted, uste(d) a su hija que me ha jugado traición.

- Llévatela, yerno mío, que la Iglesia te la dio-.

La ha cogío por los pelos y la mató. 


\section{La Virgen y el ciego}

Versión de Jerez de la Frontera. Cantada por Milagros Rego Carrasco, 63 años. Recogida en enero 1994 por Miguel Ángel Peña Díaz.

Caminito, caminito, caminito de Belén ${ }^{13}$, como el camino es tan largo pidió el Niño de beber.

-Que los ríos vienen turbios y no se puede beber,

allí arribita hay un huerto y en el huerto un aranjué ${ }^{14}$

5

y el huertero que lo labra es un ciego que no ve-.

-Ciego, dame una naranja, para callarlo a Manuel.

-Entre usted, señora, y coja para el Niño y para usted-.

Como la Virgen tan pura na más que ha cogío tres:

una le ha dado al Niño y otra para San José,

10 otra se ha quedao con ella para probarla también.

A la salida del huerto dice el ciego que ya ve.

- ¿Quién ha sido esa señora que me ha hecho tanto bien?

Será la Virgen María que camina pa Belén,

que iba de romería hasta el portal de Belén.

\section{Los primos romeros}

Versión de Jerez de la Frontera. Cantada por Milagros Rego Carrasco, 63 años. Recogida en enero 1994 por Miguel Ángel Peña Díaz.

Para Roma caminan los peregrinos

pa que los case el papa, que son primos.

Sombrerito de hule lleva el mozuelo

y la peregrinita de terciopelo.

$5 \quad$ Al pasar el arroyo de la Victoria

tropezó la madrina y cayó la novia.

La madrina se ríe y el novio llora

y en ver que se ha caído la pobre novia.

Llegaron a palacio, suben arriba,

10 en la sala de en medio lo desaniman.

Le(s) ha preguntado el papa la edad que tienen,

ella dice que quince $\mathrm{y}$ el diecinueve.

Le(s) ha preguntado el papa de qué tierra,

ella dice de Cabra y el de Lucena.

15 Le(s) ha preguntado el papa que si han pecao.

- Al pasar el arroyo le di la mano-.

..la penitencia de silla en silla,

\footnotetext{
13 Detrás de todos los primeros hemistiquios se dice «Viva el amor» y de los segundos, «Viva el laurel».

14 aranjué por «naranjel»o «naranjal»
} 
para darle la mano la peregrina.

20

-Peregrinita hermosa, vámonos de aquí

que por lo que yo veo me quedo sin ti.

\section{Blancaflor y Filomena}

Versión de Jerez de la Frontera. Cantada por Milagros Rego Carrasco, 63 años. Recogida en febrero 1994 por Miguel Ángel Peña Díaz.

Por la provincia de Asturias se pasean dos doncellas.

Ha pasado un caballero y se ha enamorado de ellas.

Se casó con Blancaflor sin desprecia(r) a Filomena.

El caballero es de tropas pa la guerra se la lleva.

$5 \quad$ Y a la venida pa'cá ${ }^{15}$ se ha llegado an ca ${ }^{16}$ la suegra.

-Buenos días tenga, suegra, yo vengo por Filomena, que Blancaflo(r) está de parto la quiere a su cabecera-. Y dándole los consejos que es mocita y doncella, ha cogido un caballo, Filomena en una yegua.

10 Y a la bajita de un cerro se encontró con una cueva. Que quiso ella, que no quiso, su gusto logró con ella. Después que logró su gusto, hizo un hoyito en la arena. Medio cuerpo la enterró, medio lo ha dejado fuera. Viva le sacó los ojos, viva le saca la lengua.

$15-i$ Si viniera un pastorcito de lejos de aquestas tierras, con pluma, papel y tinta, metida en su cartuchera!Y estando en estas razones, el pasto(r) a la vera llega. - Señora, no traigo tinta, ni pluma en mi cartuchera. -Mi lengua sirve de pluma, mis ojos de tinta negra,

20 para escribirle una carta a mi hermana que la lea-. Y estando en esta razón, el pasto(r) a la hermana llega. - Blancaflor, toma esta carta de tu hermana Filomena-. [Al coger la hermana la carta, al suelo cayó desmayada] Del mal sustito parió, lo frió en la cazuela,

25 para cuando venga Tarquino tenga la cena hecha.

-Blancaflor, ¿qué hay de cenar? - Lo que hay en la cazuela.

-Blancaflor, di la verdad, ¡qué carne más dulce es ésta!

-Más dulce era la honra de mi hermana Filomena-.

Con un puñal de dos filos la cabeza le cortaba.

30 -Y esto te lo hago, Tarquino, por mi hermana Filomena!

\section{El tío Andrés}

\footnotetext{
${ }^{15} p a$ 'cá contracción de «para acá».

16 an ca es «a casa de».
} 
Versión de Jerez de la Frontera. Cantada por Milagros Rego Carrasco, 63 años. Recogida en febrero 1994 por Miguel Ángel Peña Díaz.

En mi casa hay un viejo le ha dao por pretender.

Me ha dicho: - Remolona, ven acá y te enseñaré un bichito que tengo que era de mi mujer-.

Salí al patio chillando y a mi mamá llamé.

5 Chiquilla, ¿por qué chillas? - Bichito de tío Andrés.

— ¿Tío Andrés, ¿qué bicho es ese? -Señora, un cientopié-.

Lo llevan a la horca, lo amarran por los pies,

contri ${ }^{17}$ más le estiraban, más tieso iba él.

\section{La mujer del molinero y el cura}

Versión de Jerez de la Frontera. Cantada por Milagros Rego Carrasco, 63 años. Recogida en febrero 1994 por Miguel Ángel Peña Díaz.

-Padre cura, mi marido me quiere pisar el pie.

-Déjalo que te lo pise, si te da bien de comer.

- Me da pollito dorado con azuquita y con miel.

Padre cura, mi marido. ¿Dónde lo metemo(s) a usted?

5 - Méteme en aquel costal arrimaíto a la pared-.

A eso que entraba el marido lo primerito que ve.

- ¿Qué es aquello del costal arrimaíto a la pared?

- Fanega y media de trigo que han traído pa moler.

- Sea trigo o no lo sea mis ojos lo quieren ver.

10 - Malditos sean tus ojos que todo lo quieren ver-.

La sotana del padre cura y el sombrero del padre Andrés.

Lo amarraron a la una y lo soltaron a las tres.

Apenas que lo soltaron apartó el cura a correr,

parecía que llevaba el demonio entre los pies.

15 Al otro día siguiente a la plaza fue Isabel,

al revolver de una esquina se ha encontrado al padre Andrés.

-Padre cura, mi marido que a mi casa vaya usted.

- Vaya tu marido al infierno y tú te vayas con él.

\section{Los caminos se hicieron}

Versión de Jerez de la Frontera. Cantada por Milagros Rego Carrasco, 63 años. Recogida en febrero 1994 por Miguel Ángel Peña Díaz.

Los caminos se hicieron con agua, viento y frío;

caminaba un anciano muy triste y afligido.

Gloria, a su vendita mare Victoria

${ }^{17}$ contri por «cuanto». 
Gloria al recién nacido, Gloria.

5 Llegaron a un mesón para pedir posada

y el mesadero ingrato iba y se la negaba.

Gloria, a su vendita mare Victoria

Gloria al recién nacido, Gloria.

-Yo no doy posada, yo no doy posada,

10 a deshora la noche, ni a muje(r) embarazada-.

Gloria, a su vendita mare Victoria

Gloria al recién nacido, Gloria.

La Virgen al oír eso se cayó desmayada

y San José le dice: - Levanta, esposa amada,

15 en mientras yo esté vivo no te hará falta nada-.

Gloria, a su vendita mare Victoria

Gloria al recién nacido, Gloria.

- Si usted trae dinero, toda la casa es tuya, pero si no lo trae no hay posada ninguna-

20 Gloria, a su vendita mare Victoria

Gloria al recién nacido, Gloria.

Y desde allí se fueron a un porta(1) arrecogido, entre el buey y la mula nació el Verbo divino.

Gloria, a su vendita mare Victoria

25 Gloria al recién nacido, Gloria.

Allá ha nacido el Niño, allá en aquel pesebre entre pajas y yerbas, allí nadie le ofende.

Gloria, a su vendita mare Victoria

Gloria al recién nacido, Gloria.

30 La mula le relincha y el buey le baela y el niño chiquetito dormidito se queda.

Gloria, a su vendita mare Victoria

Gloria al recién nacido, Gloria.

\section{Madre, en la puerta hay un niño}

Versión de Jerez de la Frontera. Cantada por Milagros Rego Carrasco, 63 años. Recogida en febrero 1994 por Miguel Ángel Peña Díaz.

-Madre, en la puerta está un niño más hermoso que el sol bello, yo juro que traiga frío porque viene medio en cueros.

-Po disle ${ }^{18}$ que entre, se calentará, porque en esta tierra ya no hay claridad-.

$5 \quad$ Entró el niño y se sentó. Hizo que se calentara.

Le preguntó la patrona: — ¿De qué tierra y de qué patria?-

El niño responde: - Soy de lejas tierras,

mi madre del cielo, yo bajé a la tierra.

-Niño, te quedarás en casa como hijo destinado-.

\footnotetext{
${ }^{18}$ La $s$ es una epéntesis.
} 
10 Y el niño responde: —Eso no, señora, que tengo una madre que el cielo le adora.

- Hazle la cama a este niño en el suelo y con primor.

-No me la haga usted, señora, que mi cama es un rincón.

Mi cama es el suelo desde que nací

15 y hasta que me muera ha de ser así-.

Antes que rompiera el alba el niño se levantó

y le dijo a la patrona que se quedara con Dios,

que él se iba al templo, que esa era su casa

donde iremos todos a darle las gracias.

20 Al otro día siguiente el niño estaba en la puerta

con un saquito de trigo y en la mano una peseta

diciendo: - Señora, aquí está la paga

que yo hice anoche por la madrugada-

\section{3. ¿Dónde vas, Alfonso XII?}

Versión de Jerez de la Frontera. Cantada por Milagros Rego Carrasco, 63 años. Recogida en febrero 1994 por Miguel Ángel Peña Díaz.

—DDónde vas, Alfonso XII? ¿Dónde vas tú por ahí?

- Voy en busca de Mercedes, que ayer tarde no la vi.

-Ya Mercedes ya se ha muerto, muerta está que yo la vi, cuatro duques la llevaban por las calles de Madrid.

5 Los zapatos que llevaba eran de un rico charol que se lo regaló Alfonso el día que se casó.

\section{Marinero al agua}

Versión de Jerez de la Frontera. Cantada por Milagros Rego Carrasco, 63 años. Recogida en febrero 1994 por Miguel Ángel Peña Díaz.

Estando un marinerito ${ }^{19}$ en su divina fragata, al tiempo de echar la vela, el marinero fue al agua.

Se le presenta el demonio diciéndole estas palabras:

- ¿Qué me dieras, marinero, si te salvo de estas aguas?

5 - Por allí viene mi barco cargado de oro y plata.

-Yo no quiero tus riquezas, yo lo que quiero es tu alma.

- Mi alma es para mi Dios que me la tiene emprestada ${ }^{20}$, el corazón pa María, pa María soberana,

mi cuerpo es para los peces que están debajo del agua-.

10 Y aquí se acaba la historia del marinero y del agua.

\footnotetext{
${ }^{19}$ Detrás de cada hemistiquio, se repite «ramiré».

${ }^{20}$ La sílaba «em-» es una prótesis.
} 


\section{El cura enfermo}

Versión de Jerez de la Frontera. Cantada por Milagros Rego Carrasco, 63 años. Recogida en febrero 1994 por Miguel Ángel Peña Díaz.

Estando un curita malito en la cama

a la media noche llama a la criada.

—QQué quieres, curita, que tanto me llamas?

- Quiero chocolate y no tengo agua.

5 Coge el cantarillo y anda, ve por agua.

-El pozo es muy hondo, la soga no alcanza.

- Toma este pedazo, añádele una cuarta-.

Al llegar al pozo le picó una araña,

le picó con gusto, le picó con ganas.

10 Y a los siete meses la barriga hinchada, y a los nueve meses parió la criada, y tuvo un curita con capa y sotana.

El ama le dice: —Le pondremo(s) un ama-.

Y ella le responde: -No me da la gana,

15 que tengo dos pechos como dos tinajas

pa cria(r) a mi hijo, hijo de mi alma.

\section{Las dos mozuelas}

Versión de Jerez de la Frontera. Cantada por Milagros Rego Carrasco, 63 años. Recogida en febrero 1994 por Miguel Ángel Peña Díaz.

Estándome paseando un día por la alameda ${ }^{21}$, me encontré con dos muchachas no me parecieron feas.

Las convidé a plan blanco, dicen que blancas son ellas.

Las convidé a garbanzos, dicen que no tienen muelas.

5 Las convidé a turrón, las dos se hicieron señas.

Una pidió cinco libras, otra pidió cinco y media.

Después que se la comieron las dos se hicieron señas.

$\mathrm{Al}$ revolver de una esquina esa es la casa de ellas.

Las dos se metieron dentro y a mí me han dejado fuera.

10 Por debajo de la puerta me metieron una esquela,

en el primer renglón dice «Vaya el tonto a la alameda».

Eso me ha pasado a mí por yo fiarme de ellas.

\section{Las niñas de Medina}

${ }^{21}$ Detrás de cada verso se dice «que ya por aquí, que ya por allá» y se repite el segundo hemistiquio. 
Versión de Jerez de la Frontera. Cantada por Milagros Rego Carrasco, 63 años. Recogida en febrero 1994 por Miguel Ángel Peña Díaz.

-Madre, ¿quiere usted que vaya un ratito a la alameda

con las hijas de Medina que llevan rica merienda?-

Al tiempo de merendar se perdió la más pequeña.

¿Dónde la vino a encontrar? En una sala vacía

5 hablando con un galán, el galán le respondía:

- Quiera tu madre o no quiera, tú tienes que casar.

\section{La tonada de los huevos}

Versión de Jerez de la Frontera. Cantada por Milagros Rego Carrasco, 63 años. Recogida en febrero 1994 por Miguel Ángel Peña Díaz.

Si quiere usted que le cante la tonada de los huevos

me ha dado medio cuartillo pa mí y pa mi compañero.

Mi teniente a mí me ha dado pa que compre un par de huevos

me lo metí en el bolsillo.

\section{La gallina}

Versión de Jerez de la Frontera. Cantada por Milagros Rego Carrasco, 63 años. Recogida en febrero 1994 por Miguel Ángel Peña Díaz.

-Vecinita, vecina, vecina la del rincón ${ }^{22}$, ¿no ha visto uste(d) una gallina que ayer tarde se perdió?

No siento por la gallina, ni el dinero que costó, lo que siento por los pollos que sin madre se quedó-.

$5 \quad$ Al sacar agüita (d)el pozo la gallina hizo clo. - Vecinita, vecinita, vecina la del rincón, ya apareció la gallina que ayer tarde se perdió. Al sacar agüita (d)el pozo la gallina hizo clo.

\section{San Pedro y el cordón}

Versión de Jerez de la Frontera. Cantada por Milagros Rego Carrasco, 63 años. Recogida en febrero 1994 por Miguel Ángel Peña Díaz.

Está so Say Pedro ${ }^{23}$ sentadito al sol

en calzones blancos y afuera el cordón.

Se asoma una monja por el mirador,

\footnotetext{
22 Detrás de cada verso se dice «coroco co co, coroco co co».

${ }^{23}$ Este hemistiquio sería realmente «Estando San Pedro».
} 
se asoma otra monja por el mirador.

- ¿Qué es eso, Sa Pedro, qué es eso, señor?

-Esas son mis bolas de mi muletón, esta es la escopeta con que apunto yo-.

So Say Pedro al coro subió y a todas las monjas las palporeó ${ }^{24}$.

10 La hermana abadesa más vieja que el sol:

- Venga, so Say Pedro, también quiero yo-.

Tantas fue las monjas, se cortó el cordón.

\section{Tamar}

Versión de Jerez de la Frontera. Cantada por Milagros Rego Carrasco, 63 años. Recogida en febrero 1994 por Miguel Ángel Peña Díaz.

El rey moro tenía un hijo que Tarquino se llamaba

y de edad de quince años se enamoró de su hermana.

cayó malito en la cama

con unas calenturas malas que se la pasao al alma.

5 Un domingo de mañana su padre lo visitó:

—QQué tienes, hijo Tarquino? ¿Qué tienes, hijo del alma?

-Padre, unas calenturitas que se $\mathrm{ma}^{25}$ pasao al alma.

- Si quieres un ave de esas que vuelan por casa.

-Padre, sí que yo la quiero, pero me la baje mi hermana,

10 que si acaso me la baja, venga sola y sin compaña, porque si compaña trae mis penas son redobladas-.

Como era en el verano, la mandó en nagüitas blancas.

—QQué tiene(s), hermano Tarquino? ¿Qué tiene(s), hermano del alma?

- Tengo una calenturita que me sa pasao ${ }^{26}$ al alma.

15 - Toma esta ave que el rey padre te lo manda.

-Yo no quiero ave, ni tampoco quiero nada,

lo que quiero que te sientes un ratito en mi almohada-

Con un pañolito blanco los ojitos le tapaba.

-Déjame, hermano Tarquino. Déjame, hermano del alma,

20 que en un coro de mocitas yo he de ser la deshonrada.

\section{Bernal Francés}

Versión de Jerez de la Frontera. Cantada por Milagros Rego Carrasco, 63 años. Recogida en febrero 1994 por Miguel Ángel Peña Díaz.

Tin, tin, que llama a la puerta tin, tin que no quiero abrir,

\footnotetext{
24 palporeó por «palpó».

$25 m a$ es la contracción de «me ha».

${ }^{26} \mathrm{El}$ orden natural y sin contracción sería «que se me ha pasado al alma».
} 
Tin, tin que viene la muerte tin, tin que viene por ti.

\section{Casada de lejas tierras}

Versión de Jerez de la Frontera. Cantada por Milagros Rego Carrasco, 63 años. Recogida en febrero 1994 por Miguel Ángel Peña Díaz.

Una señorita del mantín de seda sola va a la plaza sola compra ella, tan solo el marido que compra con ella; sola hace el almuerzo, sola almuerza ella,

5 tan solo el marido que almuerza con ella; sola hace la cama, sola duerme ella, tan solo el marido que duerme con ella. A la media noche un dolor le daba y a su marido ella lo llamaba.

10 -Levántate, esposo, del dulce dormir que la luz del día ya quiere venir, la blanca paloma ya quiere parir. Maridito mío, si tú me quisieras a la tuya madre fuera(s) y le dijeras-.

15 -Levántate, madre, del dulce dormir que la luz del día ya quiere venir, la blanca paloma ya quiere parir. - Si quiere parir, que para un varón, que le brote sangre por el corazón-.

20 - Maridito mío, si tú me quisieras a la tuya hermana fuera(s) y le dijeras-. -Levántate, hermana, del dulce dormir que la luz del día ya quiere venir, la blanca paloma ya quiere parir.

25 - Si quiere parir, que para una niña que le brote sangre por una costilla-. -Maridito mío, si tú me quisieras a la mía madre fuera(s) y le dijeras-. -Levántate, suegra, del dulce dormir, 30 que la luz del día ya quiere venir, la blanca paloma ya quiere parir. -Espérate, yerno, espérate en la puerta, que voy a coger todas mis riquezas, un jarro de miel y otro de manteca-.

35 —Por qué repican tanto las campanas? - Por una señorita del mantín de seda que ha muerto de parto por mala cuñada y por mala suegra. 


\section{La doncella guerrera}

Versión de Jerez de la Frontera. Cantada por la hija de Milagros Rego Carrasco, 63 años. Recogida en febrero 1994 por Miguel Ángel Peña Díaz.

Un capitán sevillano siete hijos le dio Dios y tuvo la mala suerte que ninguno fue varón.

Un día la más pequeña le tocó la dirección.

-Padre, me voy a la guerra vestidito de varón.

5 -No te vayas, hija mía, que te van a conocer con ese pelo tan largo y carita de mujer.

- Si tengo el pelo tan largo, padre, córtemelo usted y con el pelo cortado y un varón pareceré-. Y cuatro años de guerra y nadie la conoció, 10 solo el hijo del rey que con ella se casó.

\section{La mala suegra}

Versión de Jerez de la Frontera. Cantada por Milagros Rego Carrasco, 63 años. Recogida en febrero 1994 por Miguel Ángel Peña Díaz.

Mi Carmela se pasea por una salita adelante con los dolores de parto que el corazón se le parte.

La suegra que la escuchaba que era digno de escuchar.

5

-Di, Carmela, ¿qué te pasa?

$5 \quad$...............oge tu ropa y vete a casa de tu madre.

Cuando venga Pedro yo le pondré de cenar.

[Vino y le dijo que ella estaba en casa de su madre y que le había abandonado.

Fue a casa de la suegra y le dijo que se levantara de la cama. Ella le dijo:]

- Con una hora de parida no hay mujer que se levante.

10 [La montó en su caballo y la mató.]

\section{El quintado}

Versión de Jerez de la Frontera. Cantada por Milagros Rego Carrasco, 63 años. Recogida en febrero 1994 por Miguel Ángel Peña Díaz.

Unos cantan y otros ríen y otros llevan mucha pena y el que va en medio de todos, el que más penita lleva.

Le ha preguntao el capitán por qué lleva tanta pena.

- A los tres días de casao me llevan para la guerra.

5 - ¿Tan guapa es tu mujer que tanta penita llevas?-

Le ha enseñado un retrato que llevaba en su cartera

y hasta el mismo capitán se ha enamorado de ella. 
- Toma la licencia y vete que por un soldado menos a cuidar de esa doncella

también se acaba la guerra.

\section{La huida a Egipto}

Versión de Jerez de la Frontera. Cantada por Milagros Rego Carrasco, 63 años. Recogida en febrero 1994 por Miguel Ángel Peña Díaz.

De Belén salió un niñito huyendo del rey Herodes.

Por el camino pasaron grandes frío y calores.

Al niño lo llevan con grande cuidao

porque el rey Herodes quiere degollarlo.

$5 \quad$ Siguieron más adelante y a un labrador que allí vieron

le ha preguntado la Virgen: —Labrador, ¿qué estás haciendo?-

El labrador dice: - -Señora, sembrando

un poco de trigo para el otro año.

10

- Labrador, vete a tu casa y ven mañana a segarlo

Y si por nosotros vienen preguntando

dile que nos viste estando sembrando-.

El labrador se fue a su casa y a su mujer le ha contado

todo lo que le pasaba, todo lo que le pasó.

15 Y la mujer dice: - Eso no puede ser

en tan poco tiempo sembrar y coger-.

Siguieron más adelante y a otro labrador que vieron

le ha preguntado la Virgen: —Labrador, ¿qué estás haciendo?-

El labrador dice: - Señora, sembrando

20 una poca de piedra para el otro año-.

Tanta fue la multitud que el Señor le hizo de piedra

que parecía un peñasco de grande Sierra Morena.

Ese fue el castigo que Dios le mandó

por ser mal labrador aquel labrador.

25 Estando segando el trigo pasaron dos a caballo,

por una mujer y un niño y un anciano preguntaron.

El labrador dice: - Cierto que los vi,

estando sembrando pasó por aquí-.

Volvieron caballo atrás lleno de soberbia y rabia

30 porque no pudieron coger el intento que llevaban.

El intento era de cogerlo preso

para entregarlo al rey más soberbio.

\section{La pastora y el pájaro}

Versión de Jerez de la Frontera. Cantada por Milagros Rego Carrasco, 63 años, y Salud y Dolores Oca Ramallo. Recogida el 16 de marzo de 1994 por Miguel Ángel Peña Díaz. 
Estando una pastorcilla sencilla de corazón al pie de sus ovejitas pensando en su dulce amor y vio veni(r) un pajarillo como los rayos del sol.

- iQué chiquito y qué bonito! ¡Ay si lo cogiera yo!El pícaro (d)el pajarillo después de picar la flor alza el vuelo y se arretira $^{27}$ y burlada la dejó. A eso de los nueve meses la pastorcita parió y tuvo un hermoso hijo como los rayos del sol y se parecía mucho al picarillo cantor.

\section{Un pobre a un rico pidió}

Versión de Jerez de la Frontera. Cantada por Milagros Rego Carrasco, 63 años, y Salud y Dolores Oca Ramallo. Recogida el 16 de marzo de 1994 por Miguel Ángel Peña Díaz.

Un lunes por la mañana un pobre a un rico pidió que le diera una limosna por Dio(s) y por amor de Dios.

Por Dio(s) y por amor de Dios y por la Virgen del Carmen, que le diera una limosna: -Que vengo muerto de hambre.

- Hombre de cutis tan fino y de tan pequeña edad, dime qué oficio tienes de eso de trabajar.

- Mi padre era carpintero, ese oficio yo aprendí, me sucedió una tragedia por eso me veo así.

-No es eso lo que pregunto, ni lo que voy a preguntar,

10 que me parece que es el ladrón del capitán.

Jesús fue y se descubrió $\quad$ la llaga de su costado.

El rico se arrodilló.

-Ya tarde te has acordado ya para ti no habrá perdón.

\section{Tamar}

Versión de Jerez de la Frontera. Cantada por Milagros Rego Carrasco, 63 años, y Salud y Dolores Oca Ramallo. Recogida el 16 de marzo de 1994 por Miguel Ángel Peña Díaz.

la niña malita estaba

fue su padre a visitarla un domingo de mañana.

Llamaron a los doctores, a los más sabios de España, unos dicen que se muere y otros dicen que se salva

5 y el más chiquitito dice que viene embarazada.

La metieron en un cuarto donde cosía y bordaba

${ }^{27}$ La vocal inicial es una prótesis. 
entre penas y dolores tuvo un hijo de su alma.

Llevaron a bautizarlo un domingo de mañana

y de nombre le pusieron hijo de hermano y hermana.

\section{Galán que corteja a una mujer casada}

Versión de Jerez de la Frontera. Cantada por Milagros Rego Carrasco, 63 años, y Salud y Dolores Oca Ramallo. Recogida el 16 de marzo de 1994 por Miguel Ángel Peña Díaz.

Un domingo de mañana yo fui a misa con mi padre

y en el camino encontré una mujer que era un ángel.

La seguí paso por paso a ver adónde entraba,

vi que entraba en un jardín, le dije que si me amaba.

5 -No me ame, caballero, mire usted, que soy casada

y a mi marido del alma no quiero faltarle en nada-.

Ha entrado en un cementerio, hay un pájaro ciprés

que por su boquita dice tu mamá tiene(s) a los pies.

Como no tenía lápida, tenía una cruz de madera

10 con un letrero que dice «adiós, querida Carmela».

\section{La muerte ocultada}

Versión de Jerez de la Frontera. Cantada Salud y Dolores Oca Ramallo. Recogida el 16 de marzo de 1994 por Miguel Ángel Peña Díaz.

Ahí viene don Pedro de la guerra herido

viene con el ansia de ver a su hijo.

-Hijo de mi alma, hijo de mi vida.

\section{A orillas de una fuente}

Versión de Jerez de la Frontera. Cantada por Milagros Rego Carrasco, 63 años, y Salud y Dolores Oca Ramallo. Recogida el 16 de marzo de 1994 por Miguel Ángel Peña Díaz.

A orillas de una fuente a una zagala vi, con el ruido del agua yo me acerqué hacia allí.

Oí una voz que decía «ay de mí, ay de mí, ay de mí».

Era una pobre niña dejada de un pastor

5 y después de gozarla se fue y la abandonó.

Yo dije para mí entonces «qué dolor, qué dolor, qué dolor».

A un jardín que allí había allí me la llevé,

en su divino rostro tres besos le zampé

y ella me dijo a mí entonces «otros tres, otros tres, otros tres». 
10 De un jardín que allí había tres rosas le corté, se la puse en el pecho, la mano le apreté y ella me dijo a mí entonces «ay Jesús, qué pesado es usted». En un jardín que allí había le dije mi intención, se me quedó callada, nada me contestó.

15 Yo dije para mí entonces «ya cayó, ya cayó, ya cayó».

Al despedirme de ella a mí se arrodilló

y llorando me dijo «que no me olvide, no, no».

\section{El corregidor y la molinera}

Versión de Jerez de la Frontera. Cantada por Milagros Rego Carrasco, 63 años, y Salud y Dolores Oca Ramallo. Recogida el 16 de marzo de 1994 por Miguel Ángel Peña Díaz.

En Arcos de la Frontera un molinero afamado

que ganaba su sustento con el molino alquilado.

Y era casado

con una moza y era tan bella

5 que hasta el corregidor se apreció de ella.

La visitaba,

la cortejaba y hasta que un día

se le cayó el intento que pretendía.

Responde la molinera: - Sus favores no admito,

10 porque si nos coge mi esposo nos cogerá en el carlito.

Porque el maldito tiene una llave

con la cual cierra con la cual abre

y hasta que un día

se le quitó el intento que pretendía.

\section{La asturianita}

Versión de Jerez de la Frontera. Cantada por Milagros Rego Carrasco, 63 años, y Salud y Dolores Oca Ramallo. Recogida el 16 de marzo de 1994 por Miguel Ángel Peña Díaz.

En la montaña de Asturias a una niña vi

regando sus lindas flores de mayo y de abril.

Ha pasado un caballero le pidió una flor

y la niña le contesta: —Puede ser que no.

5 Las flores de mi jardín no son para caballeros, que son para mi pechito y para mi pelo.

-Vaya usted con Dios, asturiana, me la tienes que pagar

o te corto la cabeza o la mano principal-.

Y al otro día siguiente la niña salió.

10 Se ha encontrado al caballero y se la llevó. 
-Toma, caballero, la flor de mi mano, déjame seguir con mis tres hermanos.

-No quiero flor de tu mano, ni tampoco de ti, que lo que quiero es matarte como yo te prometí-.

15 La ha cogido de la mano y se la llevó,

la ha encerradito en un cuarto y cuatro puñalás le dio.

\section{El prisionero}

Versión de Jerez de la Frontera. Cantada por Milagros Rego Carrasco, 63 años, y Salud y Dolores Oca Ramallo. Recogida el 16 de marzo de 1994 por Miguel Ángel Peña Díaz.

Yo era de catorce años, le metí fuego a mi amor, con diecisiete cumplidos prisionero me veo yo. Veinticinco calabozos tiene la cárcel de Utrera, veinticinco recorridos y el último con más pena.

5 Me sacan de una prisión, me meten en otro más malo que ni siquiera se ve ni los dedos de la mano, tan solo un pajarillo que ha nacido en esta torre cuando de día me canta, cuando de noche se esconde. Pajarillo, tú que vuelas por lo alto de la audiencia

10 dime si has visto leer la carta de mi sentencia y si la has visto leer, ven acá y dímelo porque si no me lo dices de penas me muero yo. Madre mía, madre mía, madre de los marineros, sácame de esta prisión, si no me sacas me muero.

\section{La condesita o la boda estorbada}

Versión de Jerez de la Frontera. Cantada por Milagros Rego Carrasco, 63 años, y Salud y Dolores Oca Ramallo. Recogida a finales de marzo de 1994 por Miguel Ángel Peña Díaz.

-Gerineldo, Gerineldo, por la Santa Trinidad, ¿de quién son estas vaquitas que tan solitas están?

-Son del conde Gerineldo que ya está para casar.

\section{Atropellado por el tren}

Versión de Jerez de la Frontera. Cantada por Milagros Rego Carrasco, 63 años, y Salud y Dolores Oca Ramallo. Recogida a finales de marzo de 1994 por Miguel Ángel Peña Díaz.

Juanito se fue a la banda por ver si venía el tren 
y el tren como era de noche Juanito vino a coger. Cuando el maquinista vio la vía llena de sangre llamaron a la policía, que venga el señor alcalde.

5 Ya está aquí el señor alcalde con toda su policía, los guardias municipales para registrar la vía. Lo cogieron entre cuatro, lo llevaron al hospital, el médico le responde que no lo pueden curar. - Si no pueden curar, que me peguen cuatro tiros

10 que yo no puedo vivir con el corazón partido-. La novia que estaba al lado se echó pañuelo a la cara diciendo: - Ay, Juanito, Juanito de mis entrañas. El anillo que me diste con las [...] azules tres días lo tuve puesto sábado, domingo y lunes.

\section{La enfermera}

Versión de Jerez de la Frontera. Cantada por Milagros Rego Carrasco, 63 años, y Salud y Dolores Oca Ramallo. Recogida a finales de marzo de 1994 por Miguel Ángel Peña Díaz.

Siendo yo enfermera de la Caridad curaba a un herido, grave militar.

Una noche, sola, que lo fui a curar me pidió el herido un beso na más.

5 Como me lo pedía con tanta ansiedad, yo le di el beso por la madrugá.

-Dámelo, enfermera, que me curaré, dámelo, enfermera, que me pondré bien-. Cuando se puso bueno, yo le supliqué

10 que a nadie dijera que yo lo besé, que tuviera suerte y felicidad y que se portara como un militar.

Al otro día siguiente tuve carta de él la que me decía que era coronel.

15 Pero aquel papel pronto lo rompí porque me decía «tú serás pa mí». Una noche, sola, pensativa yo fue la superiora y así me llamó, para suplicarme y me suplicó,

20 que por qué había roto el papel de amor. Y al verlo yo a él me desmayé yo, me caí al suelo y él me recogió. -Alevante ${ }^{28}$, Leonor, alevántate de aquí, que a las doce en punto vengo yo por ti,

25 que la casa está preparada ya

${ }^{28}$ La vocal inicial es una prótesis. 
con to los oficios para un militar.

\section{La lecherita}

Versión de Jerez de la Frontera. Cantada por Milagros Rego Carrasco, 63 años, y Salud y Dolores Oca Ramallo. Recogida a finales de marzo de 1994 por Miguel Ángel Peña Díaz.

Desde niña fui lechera, muy feliz y muy dichosa, criadita entre montañas cerca de Villaviciosa.

Por querer yo mucho a un hombre del mundo fui mormurada

de aquellos amores malditos que me hicieron desgraciada.

5 De aquellos amores malditos, solo me queda un recuerdo un niño de lindos ojos que es un angelín del cielo.

Cuando lo acuesto en la cuna no duerme sin que le cante

la canción de aquel hombre que anda por el mundo errante.

-No me chilles, mamaíta, cántame más despacito,

10 no quiero que nadie sepa que no tengo papaíto-.

Anoche ensoñaba yo con el fin de mis amores

que tenía cinco vacas y un nuevo jardín de flores.

Ya no subo a la montaña, ni salgo a la carretera,

no quiero que nadie sepa la vida de la lechera.

\section{La mala suegra}

Versión de Jerez de la Frontera. Cantada por Milagros Rego Carrasco, 63 años, y Salud y Dolores Oca Ramallo. Recogida a finales de marzo de 1994 por Miguel Ángel Peña Díaz.

Adelina se pasea por una salita adelante con los dolores de parto que el corazón se le parte.

Se ha asomado a la ventana y ha visto veni(r) a Jesús:

- QQuién viviera en aquel valle como María y tú!-

La suegra que la escuchaba por el ojo de la llave:

- Coge, Carmela, tu ropa y vete a casa de tu madre.

Si a la noche viene Pedro yo le diré dónde estás

y si pide de comer yo le daré de cenar-.

A la noche vino Pedro: - ¿Mi Carmela dónde está?

10 - Se ha ido an casa su madre que se ha portado muy mal, te ha puesto de sinvergüenza y te ha puesto de criminal-.

Cogió Pedro su caballo y an casa Carmela va

$\mathrm{Y}$ al subir las escaleras se ha encontrado a la comadre.

-Buenas noches tengas, Pedro, ya tenemos un infante.

15 está muerta, Dios lo sabe.

-Alevántate, Carmela. —Cómo quieres que alevante

si a dos horas de parida no hay mujer que se alevante? 
-Alevántate, Carmela, no me hagas replicarte que detrás de aquella ermita tengo intención de matarte-.

20 Se ha montado en su caballo y a Carmela por delante. Siete leguas sigue andando, siete leguas sin hablarse.

— ¿Por qué no hablas, Carmela? —Cómo quieres que te hable si los pechos del caballo van bañaditos en sangre?Al llegar a aquella ermita cuatro puñalás le dio, cuatro puñalás le dio que el corazón le partió.

$25 \mathrm{Al}$ otro día siguiente las campanas redoblaban. - ¿Quién se ha muerto?, ¿quién se ha muerto? Carmela la del infante.

- No se ha muerto, no se ha muerto, que la ha matado mi padre por un falso testamento que han querido levantarle.

\section{La mala hierba + Delgadina}

Versión de Jerez de la Frontera. Cantada por Milagros Rego Carrasco, 63 años, y Salud y Dolores Oca Ramallo. Recogida a finales de marzo de 1994 por Miguel Ángel Peña Díaz.

Adelina se pasea por una salita adelante con gargantillas de oro y el pelo que le arrastraba. En el palacio del rey hay una mata sembrada quien la pise o no la pise será la desgraciada.

5 Adelina la pisó y esa fue la desgraciada.

Estando un día en la mesa el padre que la miraba.

-Padre, ¿qué mira usted? - Hija, no te miro nada, lo que te estoy yo mirando, tú serás la desgraciada-. La metió en un cuarto oscuro, sin comida y sin agua.

10 Al otro día siguiente se asomaba a la ventana y vio a su madre venir con un cántaro de agua. -Madre, si eres mi madre, dame un poco de agua que el corazón se me seca a Dios le entrego mi alma-. $\mathrm{Al}$ otro día siguiente se asomaba a la ventana

15 y vio a su hermana venir con un cántaro de agua.

- Hermana, si eres mi hermana, dame una poco de agua que el corazón se me seca a Dios entrego mi alma.

\section{Rosarito}

Versión de Jerez de la Frontera. Cantada por Milagros Rego Carrasco, 63 años, y Salud y Dolores Oca Ramallo. Recogida a finales de marzo de 1994 por Miguel Ángel Peña Díaz.

Rosarito fue a la venta a preguntarle al ventero que si aquello era pluma o una maraña de pelo y el ventero la siguió y en la puerta de su casa 
cuatro puñalás le dio,

$5 \quad$ cuatro puñalás de muerte

que el corazón le partió.

Rosarito abre los ojos y descubre al criminal

que al pobrecito tu hermano la culpa le van a echar.

La sangre de Rosarito corría por la verbena

y así corría la sangre de Rosario la morena.

\section{El cebollinero}

Versión de Jerez de la Frontera. Cantada por Milagros Rego Carrasco, 63 años, y Salud y Dolores Oca Ramallo. Recogida a finales de marzo de 1994 por Miguel Ángel Peña Díaz.

Por las calles de Madrid pasea un cebollinero, vendiendo su cebollita para ganarse el dinero.

Fue an casa de una casada, casada de cuatro tiempos.

- Señora, dame posada, que yo posada no tengo.

5 - Mi marido no está en casa y yo posada no tengo-.

Ella quiso, que no quiso, posada le dio al mancebo.

A eso de los nueve meses la niña tuvo un mancebo

que se parecía mucho al señor cebollinero.

El padrino de este niño ha de ser cebollinero

10 de esos que venden cebollas para ganarse el dinero.

\section{Lux aeterna}

Versión de Jerez de la Frontera. Cantada por Milagros Rego Carrasco, 63 años, y Salud y Dolores Oca Ramallo. Recogida a finales de marzo de 1994 por Miguel Ángel Peña Díaz.

Un chico y una chica se paseaban y hacía muchos años que no se hablaban.

Ellos se dicen, ellos se hablan:

-Dime, querido Pepe, lo que te pasa.

5 -Lo que a mí me pasa no te lo digo porque va a ser la causa de nuestro olvido.

- ¡Ay dímelo, ay dímelo porque si no lo oyera me muero yo!

-Ya que se tan peñado ${ }^{29}$ te lo diré,

10 que estoy enamorado de otra mujer-. ¡Ay que me pesa, ay que me pesa, del tiempo que lo tuve en la cabeza!

Por el día de mi santo me regaló un corte de vestido de gran valor.

${ }^{29}$ Este hemistiquio sería así: «Ya que te has empeñado». 
15 -Madre, querida madre, ¡cuántas estrellas!

Ábreme las ventanas que quiero verlas.

-No, hija mía, no, no digas eso

que a deshora de la noche daño te pueda.

-Madre, vente a mi lado y dame un beso.

20 Antes que yo me muera te doy un encargo.

Si viene Juan a verme después de muerta,

cuidadito que entre en aquella puerta.

Que venga a mortajarme Juan y Dolores

que una no tiene culpa que Juan la adore.

25 La mortaja será de raso blanco,

los zapatos celestes con moña blanco

y también me pondrán la cruz de perlas

que le regaló Juan el día de feria-.

A las cuatro la tarde salió el entierro.

30 Juan que estaba en la puerta se metió dentro.

Ya se murió Angelina de mal de amores, la culpa la ha tenido Juan y Dolores.

-Adiós, Dolores, adiós, Dolores, que me voy con mi Adela de mis amores-.

35 Juan se fue al cementerio por verla muerta, ha dao una cantidad la desentierran.

Se ha jincao de rodillas, sacó un revólver, se tiró cuatro tiros por mal de amores.

\section{La dama y el pastor}

Versión de Jerez de la Frontera. Cantada por Milagros Rego Carrasco, 63 años, y Salud y Dolores Oca Ramallo. Recogida a finales de marzo de 1994 por Miguel Ángel Peña Díaz.

-Pastorcito, que estás en el campo comiendo pan de centeno, si te casaras conmigo, que sí, lo comieras blanco y bueno, adiós, adiós para siempre, adiós.

-Pastorcito, que estás en el campo comiendo pan de madroño,

5 si te casaras conmigo durmieras entre mi moño.

\section{La viudita del conde laurel}

Versión de Jerez de la Frontera. Cantada por Milagros Rego Carrasco, 63 años, y Salud y Dolores Oca Ramallo. Recogida a finales de marzo de 1994 por Miguel Ángel Peña Díaz.

-Pues soy la viudita del conde laurel

que quiero casarme, no encuentro con quién.

-Si quieres casarte, no encuentras con quién, 
pues coja a su gusto que aquí tiene a quién.

5 - Pues cojo a Dolores por ser la más bella y blanca azucena de mayo y abril.

Fecha de recepción: 25 de febrero de 2019

Fecha de aceptación: 26 de marzo de 2019

$$
\text { j }
$$

